\title{
Teaching Practice and Perception on Senior Seminar for Professional and Technical Personnel for Local Mechanical Manufacturing Industry
}

\author{
Tie-Jun Zhang ${ }^{1, a}$, Ying Guan ${ }^{2, b^{*}}$ \\ ${ }^{1}$ Research Institute of New Materials Technology, Chongqing University of Arts and Sciences, \\ Chongqing 402160, China; \\ ${ }^{2}$ Library, Chongqing University of Arts and Sciences, Chongqing 402160, China. \\ aztj1965@tsinghua.org.cn, b2439719791@qq.com \\ Corresponding author: Ying Guan
}

Keywords: Teaching practice, professional and technical personnel, continuing education

\begin{abstract}
Mechanical manufacturing industry is one of the main developments of Chinese economic growth. Scientific and technological innovation driven manufacturing upgrading is the key for Chinese manufacturing industry from large to strong, and more importantly, it is to train the professional and technical personnel in this field. The teachers in Chongqing University of Arts and Sciences have tried to improve teaching methods and apply modern means in teaching practice, aiming at enhancing professional and technical personnel students' innovation for study and improve teaching effect. As a result, the practice develops students' innovative spirit and helps them to meet the demands for comprehensive abilities of professional and technical personnel. Through the teaching practice of undertaking municipal and national level continuing education for professional and technical personnel, the working experience of continuing education can be summarized as follows: Firstly, strenuously serve for professional and technical personnel's knowledge update project, departments at all levels catch condominium together and make unity and cooperation. Secondly, elaborately design the content on the basis of transformation of enterprises and application of new materials and technologies. Thirdly, catch organization, management and service work. Last but not the least, timely collect trainees' feedback and evaluation information. These provide some new thoughts to improve the quality of training and teaching professional and technical personnel in local manufacturing industry.
\end{abstract}

\section{Introduction}

Along with the acceleration of the globalization process, the relationship between economy and education becomes closer day by day. China is now at a crucial point when we are fully building a well-off society, quickly transforming the pattern of economic development and comprehensively deepening its reform. As a result, we need higher education to supply the frontline serve of modern production with applied, inter-disciplinary and innovative talents, who not only master modern science technology but also has received a system of skill training, especially the professional and technical personnel in the top of the industry chain. The decision at the 3rd plenary session of the 18th central committee of CP is to comprehensively deepen its reform. So during the process of innovation driving and transformation development in China, the Research Institute of New Materials Technology, Chongqing University of Arts and Sciences is not a research center, but also an education center. The key thing which we have explored for a long time is that how to play a further role in servicing the local economic society. In recent years, the awareness of the new universities to run schools on local is weak. Influenced by the experience and thought of the traditional universities, new universities pursue high level, large scale and overall field schools. Generally, they get far away from the thinking of the local. Therefore, the time of the discussion and re-understanding of the local is not long.

First, it is the objective demand of the rapid development of knowledge economy for the local universities to train professional and technical personnel. With the rapid development of knowledge economy, the economic development of our country has turned to depend on the intensive technology 
and intensive knowledge instead of the natural resources. Also, colleges are now cut themselves from the economic development, but face the economic development of the dominate economy. This is a new era, where the development of the higher education and the economic society are combined together firmly. The development of economic society does not just rely on researchers, but more on those people, who apply, implement and realize the modern technique. The needs of society for talents are always changing, so the quality of the professional and technical personnel now has already slow down the speed of the economic development. According to their self-position, local universities must adjust themselves to adapt the changes of the economic development and the industrial structure, and explore the new ways of training application-oriented personnel. From then on, we conducted the exploration and practice in conducting the engineering of updating the professional and technical personnel' knowledge.

Second, training high quality technical personnel for regional economic development is the mission of application-oriented university. As our higher education has changed from elite education to mass education, application-oriented university conform to the trend of higher education and create a huge room for growth of the school transformation. Therefore, in order to study the concept of scientific development to meet the needs of the economy and society development, and in order to seize the opportunity to realize the characteristic development of school, it is a accurate positioning and a smart move to conduct the engineering of updating the professional and technical personnel' knowledge.

\section{The Objective Demand of Transformation for Local Application-orented University}

Background. China has stepped into period of mass education. In 2020, the gross matriculation rate of higher education will be $40 \%$. The book, Outline of the National Medium-and Long-term Program for Education Reform and Development, says that we should establish a system of classified management for higher education, speed up to establish a system of modern vocational education, and focus on expanding the scale of the training for application-oriented professional and technical personnel. So, for China's modernization drive, we need a large number of innovative personnel and also millions of skilled personnel. Those personnel can apply important science achievements to the fields of production and daily life to promote industrial transformation upgrading and the development of economic society. Therefore, mass higher education needs speed up the transfer, application and accumulation of advanced technology. One of the major tasks for mass higher education is to training high quality technical talent in front line of production. The construction of university has been on the agenda of China. To conduct Chinese characteristic application-oriented university, we should learn from foreign universities, accumulate technological innovation and integrate into the development of regional industry, based on the needs of real economy development. That is to conduct the system of training personnel, an overpass to conduct the growth of personnel, and an essential part to create a room for the growth of front line labors. The higher education system and structural reform must focus on the close relationship between the drive of training talent in colleges and universities and the needs of the economic society.

Industry-academy-research cooperation. It is bound to pass a long and hard time to conduct local application-oriented university to promote the development of transformation in local higher education institutes. Certainly, it will also meet many problems, difficulties and challenges. So our government, industry and community need reach a consensus and gather together, with more courage, confidence and determination, to reform local higher education institution, to integrate education with production and conduction transformation development. We are having some effect at present. For example, we have provided CSIC Red Oil Machinery Co., Ltd. with PVD commodity supply coating, which prolongs the piston pump life. We also have done the work for the failure analysis as well as the diagnosis and countermeasures on that the key part roller fractured during production, such as providing China Merchants Aluminum (Chongqing) Co., Ltd with the direct evidence of large roller's breaking, which helps the company claim successfully and avoid a great economic loss, and so on. 
The Demand of Regional Industry Development. The automobile and motorcycle industry is the main industry in Chongqing. As a district far from main city, Yongchuan is the place where plants in main city have been relocated. According to the survey in Bishan, Qinggang, Dazhu, Da'an and Shanjiao which are towns in Yongchuan, by the machinery industry and dozens of companies, we know that from 2010, most new graduates universities are unwilling to work at these local companies. Medium and small private companies or joint-stock materials processing companies are badly lack of the relevant technical staff. In these companies, the detection technology is poor, and the current technicians cannot update their knowledge as soon as possible. As the only local university in Yongchuan, our school has made a target for establishing a regional, application-oriented and multi-subject university, and taken a development strategy for "holding up the heavens and supporting the earth" development. "Holding up the heavens" is to set up excellent characteristic subjects, based on the needs of the local economic and cultural development. "Supporting the earth" is to root in the cultural development to train application-oriented personnel for local economic and cultural development. It is our goal to root in Yongchuan, serve Chongqing, and face with the whole China. Since 2010, Academician Tu has given lectures on materials new technology in Yongchuan and Dazhu. Under the leadership of the academician, Tu Mingjing, research institute of new materials technology has done a lot of preliminary survey and the preparation work in, in order to implement The Mid-to-Long Term Development Plan for Training Professional and Technical Personnel in Chongqing(2016-2020), to train high level personnel for machinery manufacturing, to strengthen the ability of independent innovation and the ability of comprehensive competition in manufacturing organizations in Chongqing, to promote the improvement of industrial technology, and speed up the transformation and upgrading of companies.

\section{Layout of Text the Exploration and Practice in Updating the Professional and Personnel' Knowledge}

Under the rapid development of knowledge economy, We have explored the training mode of the engineering for updating the professional and technical personnel' knowledge, deepen the security of training system and the reform of teaching content, strengthen the training of practical ability and improving the occupation quality of the talent. We have held the senior seminars for updating the professional and technical personnel' knowledge successfully, which are shown in table1.

Table 1 Continuing education practice for professional and technical personnel

\begin{tabular}{|c|c|c|c|}
\hline Numble & Time & Participants & District distribution \\
\hline 1 & $\begin{array}{c}2016 \\
\text { Jun }\end{array}$ & 63 & $\begin{array}{l}\text { Bishan,Dazu,Dadukou,Yubei,Jiulongpo, ect } 12 \text { districts } \\
\text { altogether. }\end{array}$ \\
\hline 2 & $\begin{array}{c}2015 \\
\text { July }\end{array}$ & 60 & Qijiang,Wanzhou,Yuzhong,ect 10 districts altogether. \\
\hline 3 & $\begin{array}{c}2014 \\
\text { July }\end{array}$ & 85 & $\begin{array}{l}\text { Beijing, Tianjing, Schuan, Guizhou,Guangdong Rongchang, } \\
\text { Heilongjiang, } 13 \text { province and municipality cities. }\end{array}$ \\
\hline 4 & $\begin{array}{c}2014 \\
\text { Jun }\end{array}$ & 60 & Dianjiang,Wanzhou, Yuzhong,Dazu,18 districts altogether. \\
\hline 5 & $\begin{array}{c}2013 \\
\text { Dec }\end{array}$ & 58 & $\begin{array}{l}\text { Bishan, Dadukou, Jiangjin, Dazhu, Yubei, ect } 8 \text { districts } \\
\text { altogether. }\end{array}$ \\
\hline
\end{tabular}

Among them the paper of technology study was collected into the Collection of outstanding papers written by four students , Huang Li from CSIC Chongqing Hydraulic Machinery Co., Ltd, Zhao Yong from Huayi Machinery Casting Co., Ltd, and Liu Liang from Xintai Machinery Co., Ltd. This seminar plays an active role in training high level talent for machinery manufacturing, strengthening the ability of independent innovation in manufacturing organizations in Chongqing, promoting the improvement of industrial technology, speeding up the transformation and upgrading of companies, and promoting the industry group development. At the same time, it broadens the companies' awareness of our new founded local university, Chongqing University of Arts and Sciences. According to the plan for the senior project of the engineering for updating the professional and technical personnel' knowledge of Chongqing, Chongqing human resources and social security bureau and Chongqing economic and information commission has been authorized 
Chongqing University of Arts and Sciences to host the 2014 advanced training class for the popularization and application of the whole city advanced Engineering materials and Manufacturing technology in mechanical manufacturing industry. This training class has been approved to become the base of the engineering for updating the professional and technical personnel' knowledge of Chongqing, and won the approval of human resources and social security to undertake the project of 2016 professional and technical personnel of national advanced training. Next year, we go on to hold the senior seminar.

\section{Summary}

Conclusions should state concisely the most important propositions of the paper as well as the author's views of the practical implications of the results. It is an important trend of the development which is environmentally friendly to industry, seeks characteristics, and strengthens application, for both the domestic and the foreign, to establish the senior project of the engineering for updating the professional and technical personnel' knowledge and construct the training system for high level application-oriented talents. Our university has conducted a theoretical study and a practical exploration of the engineering for updating the professional and technical personnel' knowledge, preliminarily and effectively, which laid a foundation for the research.

The transformation has just begun. We have to face history and reality, breaking through in trouble, developing in reform and innovation. As positioning is clear and direction is clear, we should expand the senior project of the engineering for updating the materials engineering technicians' knowledge, following our own path. We will finally realize the vision that we can try our best to do something for the progress and prosperity of the mechanical manufacturing industry.

\section{Acknowledgements}

This work was supported by Science Research Foundation Program (Grant No. R2012CJ19) and Teaching Reform Project (Grant No. 130334 and 140348) of Chongqing University of Arts and Sciences, Research Foundation Program (Grant No. Ycstc,2015ac4002) of Yongchuan Science and Technology Commission in Chongqing. The authors also thank the Chongqing Association for Science and Technology for the financial support in scientific and technological innovation activities in Yongchuan, Chongqing Human Resources and Social Security Bureau and Ministry of Resources and Social Security of the People' Republic of China for the financial support in the year of 2013, 2014, 2015 and2016.

\section{References}

[1] 13th Five-Year plan of the People’ Republic of China. the Xinhua News Agency.20160318

[2] Mingjing Tu, Di Xu and Ying Tang, The strategy of low-competition and non-competition areas in science and technology, Chongqing Higher Education Research. 1(2013) 32-35. (in Chinese)

[3] Zeping Sun, Guixin Qi and Wanguo He, Practicing and exploring of applied talent cultivation system building__ _taking Chongqing University of Arts and Sciences as an example, Chongqing Higher Education Research. 1(2013) 54-58. (in Chinese)

[4] Liang Liu. \& Tiejun Zhang. Failure analysis of fracture roller in 700mm for a rolling mill. Journal of Chongqing University of Arts and Sciences. 38(2014)105-108. (in Chinese) 